\title{
Using the information superhighway to support organizational learning: content, context, and infrastructure
}

\author{
Leonard M. Jessup and Joseph S. Valacich \\ Department of Accounting and Information Systems \\ School of Business, Indiana University \\ Tenth and Fee Lane, Room 560 \\ Bloomington, Indiana 47405-1701 \\ Tel: 812-855-2691/812-855-8966 - Fax 812-855-7332 \\ LJESSUP@INDIANA.EDU and VALACICH@INDIANA.EDU
}

\begin{abstract}
There are a variety of computing and networking technologies available to support organizational learning, including the Internet, World Wide Web, Group Support Systems, Groupware, and Desktop Video Conferencing. These technologies can be used to help organizational members enhance their own knowledge and skills, to enable the organization as a collective to learn and grow, and to support interorganizational learning. In this paper we describe an executive education program that is focused on the content area of the virtual organization and uses technology supported learning as the primary vehicle. In this way the participants would use the technology to learn about the technology and its role in organizational learning. The available technologies described here could be used to radically change the learning infrastructure, which could enable a variety of learning modes and uses. Consequently, it may be more appropriate to think of organizational learning happening across time and space rather than in a particular place and/or at a particular time.
\end{abstract}

\section{Keywords}

Information Superhighway, Internet, World Wide Web, Group Support Systems, Groupware, Desktop Video Conferencing, Organizational Learning, Executive Education 


\section{INTRODUCTION}

Doing more with less, while still remaining competitive, has become a standard operating procedure for managers. To cope, managers have traditionally used information systems to automate old business processes. Times have changed. Managers are currently employing business process reengineering, organizational downsizing or rightsizing, total quality management, and a host of other management techniques which utilize information technology as the engine of productivity, the vehicle for organizational memory and learning, and the enabler of organizational change and competitive advantage. Now more than ever, the strategic management of information technology is key.

Among the new information technologies that show the greatest promise are a suite of telecommunication and computer-based systems that include desktop video conferencing, Groupware, and the Internet World Wide Web. These technologies can be used to transform a traditional, rigid organization into a virtual organization, which we define for this paper as an organization that uses a variety of information technologies to cross, extend, or do away with boundaries, to overcome limits and barriers, and to enable real time collaboration across space and time. This paper describes how these technologies can and should be used to support organizational learning in the form of a "high tech, high touch" executive education program. We first briefly review what is meant by organizational learning. Next, we describe the relevant content, context, and infrastructure for an executive education program that enables such learning to take place as part of, and as a result of, the education program. Finally, we conclude with a brief summary of the benefits and implications of technology supported organizational learning.

\section{ORGANIZATIONAL LEARNING}

An organization learns if, through its processing of information, the range of its potential behaviors is changed (Huber, 1991; Hoffer and Valacich, 1993). Organizational learning is based in four related constructs:

1. knowledge acquisition - obtaining knowledge,

2. information distribution - sharing information which leads to new information or understanding,

3. information interpretation - information is given one or more commonly understood meanings, and

4. organizational memory - means by which knowledge is stored for future use (Huber, 1991).

In other words, organizations learn by encoding inferences from history (memory) into routines that guide behavior (Levitt \& March, 1988). Behavior is an evoked, repeatable response and is an adaptation of stored routines, much as the muscles of an athlete learn certain moves without the overt direction of the brain. Behavior is purposeful, and is viewed as picking an appropriate action from matching the current situation (pattern) with past situations (patterns), rather than consciously choosing among alternatives. Actions are extensions of history, more than the result of anticipating the future.

Organizational learning deals with either cognitive changes or behavioral changes by the organization (Fiol \& Lyles, 1985). Cognitive change results in new shared understandings and conceptual schemes by organization members; behavioral changes are a change in the range of 
potential behaviors of organizational members (Huber, 1991). The literature on organizational learning has been summarized as reflecting two basic perspectives: the systems-structural perspective and the interpretive perspective (Daft \& Huber, 1987).

The systems-structural perspective emphasizes the acquisition and distribution of information as a resource that is necessary for learning. The systems-structural perspective focuses on the process of learning. Message routing (the distribution of messages) and message summarizing (compression of ideas without loss of meaning) are important processes. The interpretive perspective focuses on a deeper reason for information exchange. In the interpretive perspective, information has utility, as it can reduce uncertainty and equivocality, and can therefore change one's understanding about the external world (Daft \& Macintosh, 1981). Uncertainty can be simply defined as the absence of information. This is distinct from equivocality, which can be defined as the existence of multiple and conflicting interpretations about a situation. Uncertainty and equivocality are reduced, in part, by collecting and organizing information into shared repositories.

Many factors influence the ability of technology-based aids to support the information gathering, equivocality reduction, and subsequent understanding processes. Factors such as the capacity of the communication channels available (media richness), the flexibility of the representation schemes, and the ease of sharing information among group members all influence information gathering and understanding.

Organizational learning, thus, can be viewed as the acquisition and sharing of assumptions and cognitive maps among organizational (group) members (Shrivastava, 1983). Learning can occur when individuals compare their own assumptions and maps to what actually occurs. This comparison may result in two types of learning, single- and double-loop learning (Argyris \& Schon, 1978). In single-loop learning, misconceptions are corrected (facts changed) within a fixed infrastructure. In double-loop learning, organization norms, strategies, assumptions, and structures are fundamentally changed. Double-loop learning requires greater flexibility that supports dynamic changes to both the structure and content of the repository. The constraints of using technologybased aids as a foundation for organizational learning may cause learning to be systematic and restricted. Yet, as technology evolves, the ability of technology-based aids to effectively support organizational learning processes will be enhanced.

Double-loop learning is more fundamentally action-oriented and, thus, may be more desirable for an organization anxious to improve. Indeed, Garvin (1995) argued that a learning organization is one that "is skilled at creating, acquiring, and transferring knowledge, and at modifying its behavior to reflect new knowledge and insights...without accompanying changes in the way that work gets done, only the potential for improvement exists." (p. 80) For example, Garvin describes Boeing's Project Homework, for which employees collected in a notebook the "lessons learned" from previous development projects and subsequently used this knowledge to build the 757 and 767 , the most successful, error-free launches in Boeing's history.

Information technology plays a critical, enabling role in this action-oriented, double-loop learning. As Zuboff has shown (1984), to use information technology this way means that we move beyond mere automating - using Information Technology to do faster and cheaper what we did before. We must use the technology for informating - to improve what we did before AND also to learn about and change how we do things. For example, a new computer-based loan application data base enables us to process loans faster and with fewer errors. In addition to this automating, the new system also creates information about the process, which enables us to better understand the patterns of the data, decisions, and the entire process so that we can better monitor, control, and change the process. Similarly, many organizations are using the Internet (e.g., e-mail, on-line discussion groups, Web-based feedback forms) to conduct a real-time dialogue with customers so that they can 
continually improve products and services and improve brand image, recognition, and loyalty (Bessen, 1993; McKenna, 1995). Indeed, McKenna (1995) argued that, "The dialogue is the brand..." (p. 92).

Before a firm can become a learning organization, its members must fundamentally learn how to learn and, second, learn how technology can help. One effective form of instruction for organizations is the use of intensive, tailored executive education programs. Below we describe the content, context, and infrastructure for one such proposed program. This design of this approach is guided by our teaching of these topics in undergraduate and graduate courses and in teaching related topics in existing executive education programs. This is necessarily exploratory; the proposed program would have to operationalized and refined as needed.

\section{CONTENT}

There are several ways to define content in this instance, so some explanation is necessary. We are proposing an executive education program for which instructors and participants will use a variety of technologies throughout. The content of study for this program is the virtual organization, including the relevant technologies and issues. Given this content and the process that the participants will go through, the participants will have learned a lot about how to transform their own organizations into learning organizations.

Focusing on the virtual organization as the content of the education program seemed to be a reasonable place to begin. The content of a technology supported educational program could involve literally anything in or about the organization. For example, organizational members could use technology as a vehicle for learning about continuous quality improvement, strategic planning and competitive advantage, interpersonal communication and team building, and a myriad of other content areas. One particularly interesting and important set of content issues, and a reasonable place to begin with such learning, involves learning about the technologies that make organizational learning possible. Thus, below we outline the sample content goals for an educational program that is focused on the virtual organization and is based technologies that enable this type of organization. Programs to support organizational learning in this area would be designed to help managers to:

- adopt, implement, use and manage information technologies that are key to the virtual organization

- use these advanced decision and communication technologies to improve organizational productivity, memory, and learning, to shorten cycle times, to enable organizational change, to support the organization's strategic plan, and to achieve competitive advantage

- manage continual technology-driven change

- develop a vision of the future for how these technologies will influence managers, organizations, the economy, and society

\section{CONTEXT AND INFRASTRUCTURE}

Below we describe several relevant technologies and how they can be used to support real-time, interactive organizational learning. For the proposed program, the content of the learning is the virtual organization. The participants are literally using the technology to learn about technology (i.e., they learn with, through, and about the technology in this case). Keep in mind that the 
technological infrastructure could also be used to learn about other content areas, but the virtual organization as a content area is chosen here as a reasonable place to begin.

The technologies used to deliver this infrastructure would include Group Support Systems, Groupware, Desktop Video Conferencing, and the Internet World Wide Web. These technologies are being used in business to compress time, to enable collaboration across time and space, and, in some cases, to improve collaboration. For these same reasons, these technologies are used to support the proposed educational program. Each of these different technologies is described below. Sample tools for each technology category are also discussed. We use as a foundation the distance learning infrastructures already used by many institutions, including the Open University. The infrastructure builds on these by making extensive use of the Internet, World Wide Web, and multipoint interaction among instructors and participants.

\section{Information Superhighway}

The electronic information superhighway is a developing collection of interconnected, high speed digital networks around the world. It is a highway in that it will be a way to ship large amounts of various kinds of data from one place to another. In reality, it is more like a system of highways, which is typically comprised of a lot of individual roads, streets, byways, highways, and freeways, each with different characteristics and each "locally" developed and maintained. The information superhighway is being developed primarily by corporations in the digital communications and related industries. Thus, it is envisioned as a vehicle for broadcasting interactive entertainment and shopping into the home, and for seamless, international, interactive video conferencing. The information superhighway now includes, and is being constructed on top of (or along side of), the Internet.

\section{Internet}

The Internet is a global network of computer networks that is currently being used to move packets of information (text, graphics, audio, video) back and forth. Among the many features of the Internet are electronic mail, listserves (e-mail distribution lists used for discussions of particular topics), file transfers, telnet (a user logs on one computer by accessing it from another), newsgroups (bulletin boards containing discussions on a variety of topics), information searches, and information retrieval. There are an estimated 30 million users accessing the Internet from well over 20,000 unique networks, with a near doubling in subscribers reported each year. The Internet, as a whole, is not a commercial enterprise and is not sponsored by any government, although the Internet is now being used for electronic commerce and pieces of the Internet are subsidized by public universities. In addition, the Internet is not administered or regulated by any one organization or association; rather, the Internet functions and evolves based on consensus, tradition, natural selection, and the generosity of various sites and people.

\section{World Wide Web}

The World Wide Web, thought by many as the Internet's "killer application," provides easy, fast, graphical access to an ever expanding cornucopia of information sources (text, graphics, audio, video) located throughout the world, each having a unique address and each with the capability of being linked (using hyper text) with any other piece of information anywhere else on the net. Some of the related tools that could be used in the program described below include Web server software (e.g., Netscape Communication Server), Web browsers (e.g., Netscape Navigator), Web document editors (e.g., HotJava and HotMetal), Web programming tools (e.g., Java), file transfer applications 
(e.g., WSFTP), and search tools (e.g., InfoSeek and Lycos). Like the Internet and the Web, the technologies described below also support collaboration.

\section{Group Support Systems}

Group Support Systems are computer-based information systems which are used with group decision making and facilitation methodologies to support intellectual, goal-directed, collaborative work (for discussion see Jessup \& Valacich, 1993). A GSS typically consists of personal computers interconnected via a local area network with software that supports work group processes such as the interactive generation, evaluation, and organization of ideas, several methods for ranking or voting on alternatives, interactively composing and editing text together, or interactively creating and modifying graphic images. GSS are typically housed in a facility which includes audio/visual presentation support and printing capabilities and is dedicated for same time, same place computersupported group work. GSS for distributed group work, where the group members interact with each other using the system from different places and/or at different times, have recently become available. Some GSS products which could be used for the program below include Ventana's GroupSystems and Option Technologies' OptionFinder. In addition, there are now test versions of GSS-like tools for collaboration over the Internet's World Wide Web.

\section{Groupware}

Groupware software tools also support group member collaboration, but these tools are designed to provide more general, less goal-directed support to work groups. Groupware tools typically provide one or more of the following three types of support: communication, group management, or resource sharing. Communication includes features such as computer conferencing and electronic mail. Group management includes features such as scheduling and project management. Resource sharing can include the sharing of hardware, software, documents, data, and so on. Lotus Notes, considered by many to be the Groupware standard, would be an ideal form of Groupware for the program described below

Notes is designed to run across an organization's wide area network (a collection of local area networks), and also enables remote group members to dial in via modem and PC and continue to collaborate electronically with the rest of the group. In addition, Lotus is now beta testing InterNotes, an application which will allow users to use Notes applications over the Internet's World Wide Web.

\section{Desktop video conferencing}

Desktop video conferencing systems with fully integrated interactive collaborative software have recently emerged as a viable technology. These systems represent a merging of several technologies that have existed independently, but not in a fully integrated fashion. Desktop video conferencing systems represent a convergence of video conferencing, collaboration support software, and audio, all packaged in a familiar personal computer. The most unique feature of these systems is the collaboration-support software that allows remote parties to jointly (and synchronously) work on documents, spreadsheets, and graphics (i.e., any Microsoft Windows-compatible software) via an increasingly common ISDN (Integrated Services Digital Network) telephone call. Through the collaboration support software, either party can control the application program and any changes are immediately reflected on both screens. Sample systems include Intel ProShare and AT\&T Vistium.

With the use of these technologies to deliver the infrastructure for learning, the organizational members are no longer restricted to traditional contexts for learning. Traditionally, learning within the organization took place either within formal education and training settings (e.g., corporate 
classrooms and executive education programs at universities) or happened informally via mentoring, stories, legend, and so on. For the learning program, proposed here, the context is not restricted to a "classroom" in the organization or a university. Indeed, the classroom is now virtual. In addition to changing the context of learning, the technologies used also enable a variety of modes of learning, from traditional lecture format, to real time distributed collaboration, to individual deliberation supported by on-line research. Each participant will have a high-end personal computer at their place of work, with Internet connection, multi-media equipment, and desktop video conferencing equipment. These computers will be configured so that each participant can quickly and easily use their computer to interact with instructors and other participants located at other sites.

This program will be delivered in three phases (see Figure 1). In the first phase, delivered via distance learning technologies, each participant works from their own office. Each participant masters a foundation knowledge base on the virtual organization. This knowledge base will consist of a physical readings packet, some on-line readings, and links to various sites on the Web. In addition, each participant will complete an on-line self and organizational assessment with regard to their readiness for the shift to a virtual organization. Throughout this phase each participant will also interact with the instructors and other participants to better understand the course and get to know each other. They will each do so using desktop video and computer conferencing, Groupware, and the Internet World Wide Web from their own computer in their own location.

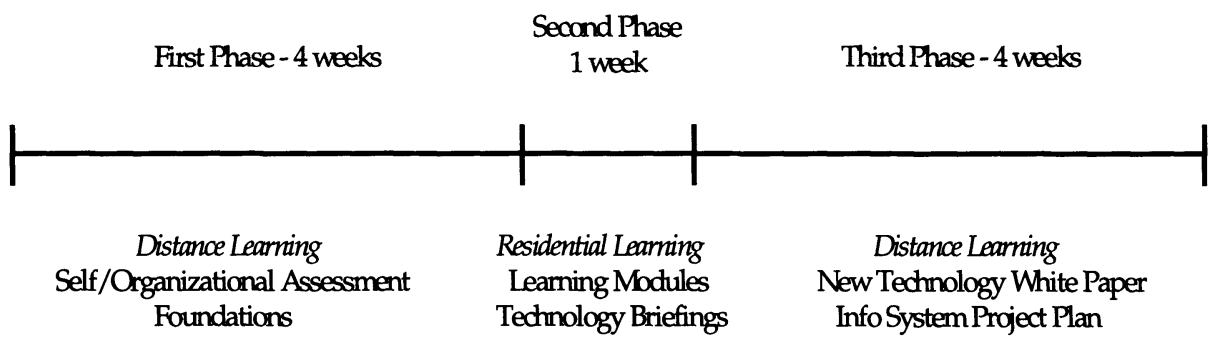

Figure 1 Three phases of proposed executive education program.

Because it is still useful and necessary for face-to-face interaction, the second phase of the program is a one-week, residential seminar series on the virtual organization. Participants will attend same time, same place seminars covering four modules: The Virtual Organization, The Virtual Office, The Virtual Team, and The Virtual Marketplace. In each module participants will consider, "what are the relevant technologies and issues," "why are they important and useful," and "how can they best be adopted, implemented, used, and managed." Participants will share ideas and information with others and gain content area knowledge which builds on their foundation knowledge. This phase will include short lectures, discussions, exercises, case studies, group projects, presentations, and technology briefings. Figure 2 presents descriptions of the primary modules of the second phase. 


\begin{tabular}{|c|c|c|}
\hline Module & Description & Disciplines \\
\hline $\begin{array}{l}\text { The Virtual } \\
\text { Organization }\end{array}$ & $\begin{array}{l}\text { How technology is enabling organizations to reshape and } \\
\text { eliminate boundaries, both within and across the } \\
\text { organization. Topics include: using technology for } \\
\text { business process reengineering, rightsizing, change } \\
\text { management, organizational memory and learning, and } \\
\text { strategic management }\end{array}$ & $\begin{array}{l}\text { Info Systems } \\
\text { Operations } \\
\text { Management } \\
\text { HR }\end{array}$ \\
\hline $\begin{array}{l}\text { The Virtual } \\
\text { Office }\end{array}$ & $\begin{array}{l}\text { How technology can enable the virtual office. Topics } \\
\text { include: Using computing and telecommunications } \\
\text { technologies to move the office into the home or into the } \\
\text { field, telecommuting, human resource (HR) issues (e.g., } \\
\text { motivation, monitoring, evaluation). }\end{array}$ & $\begin{array}{l}\text { Info Systems } \\
\text { HR }\end{array}$ \\
\hline $\begin{array}{l}\text { The Virtual } \\
\text { Team }\end{array}$ & $\begin{array}{l}\text { How technology enables any time, any where team member } \\
\text { computing. Topics include: using distributed Group } \\
\text { Support Systems, Groupware, workflow automation, } \\
\text { scheduling, desktop video and computer conferencing. }\end{array}$ & $\begin{array}{l}\text { Info Systems } \\
\text { Management } \\
\text { HR }\end{array}$ \\
\hline $\begin{array}{l}\text { The Virtual } \\
\text { Marketplace }\end{array}$ & $\begin{array}{l}\text { How to conduct and the ramifications of electronic } \\
\text { commerce. Topics include: Information Superhighway, } \\
\text { Internet, World Wide Web, Electronic Data Interchange, } \\
\text { electronic commerce, network security. }\end{array}$ & $\begin{array}{l}\text { Info Systems } \\
\text { Marketing } \\
\text { Accounting } \\
\text { HR } \\
\text { Finance } \\
\end{array}$ \\
\hline
\end{tabular}

Figure 2 Descriptions of the primary modules of the second phase.

For the third phase participants go back to their own locations and, again, collaborate via the distance learning technologies. Participants complete a New Technology White Paper and a Project Plan on a technology of their choice. For example, a participant might write a white paper on a new Groupware technology, such as Lotus Notes, and then develop a plan of how and why that technology should be implemented in his/her own organization. To accomplish this the participant will likely use their newly acquired Web skills to surf the Web for, for example, information on Notes products, case studies, and related technologies. Throughout this phase participants will continue to work with and learn from the instructors and other participants, but they are able to do so from their own organizations. For example, each participant would periodically meet via desktop video conferencing with their instructor for general project guidance and to address difficult or complex issues and questions. In addition, participants could interact in this way with other participants to "compare notes" on their final projects. E-mail could also be used for "leaner" messages passed among instructors and participants.

After the program is completed, all content materials (e.g., readings, student papers, and so on) are kept on-line for reference by future learners and instructors. In addition, the former learners and instructors are also on-line and available to current learners and instructors. By archiving content and linking former and current participants, the organization further supports learning. 
There are a variety of computing and networking technologies available to support learning in organizations. These technologies can be used to help organizational members enhance their own knowledge and skills, to enable the organization as a collective to learn and grow, and to support interorganizational learning. The content of such technology supported learning can vary, but it makes sense to begin with the technologies themselves. In this proposal we described technology supported learning which focused on the virtual organization as content. In this way the participants would use the technology to learn about the technology. The available technologies described here could be used to radically change the learning infrastructure, which could enable interactive, realtime learning in a number of modes. For example, there could be individual, self-paced learning, supported efficiently through a variety of electronic modes. Alternatively, interaction among learners and instructors could be supported in a variety of modes, creating a virtual classroom. Consequently, the context for learning will change too. It may be more appropriate to think of organizational learning happening across time and space rather than in a particular place and/or at a particular time.

There are a variety of benefits that can accrue to an organization with enhanced capabilities for technology supported learning. Essentially, individuals within the organization can learn faster and better from each other and from individuals in other organizations. More important, perhaps, the benefits can go beyond organizational learning. Because learning is the foundation for other things, technology supported organizational learning can also help organizations to operate more effectively and efficiently. For example, imagine having a sales representative, his/her manager, an engineer, and a customer, linked together via desktop video conferencing running on their PCs. Because they can interact face-to-face while being separated geographically, and because they can also simultaneously collaborate using their PC software tools or any data, they could solve a mutual problem quickly and, perhaps, better than they might have if they had to play telephone tag and explain and re-explain the problem to each others' voice mail message boxes. Technology supported learning could help here to solve problems faster and could directly improve service quality. Such real time learning has become essential to firms trying to gain or sustain competitive advantage.

One important implication of technology supported organizational learning is that it provides a new way to learn and change. Indeed, the emphasis would be on continually learning and changing, which may be difficult for some individuals. Further, such technology would also provide a new way to work, manage, and organize. Managers would need to change their expectations of how, where, and on what time frame work gets done. With technology supported organizational learning an employee could be incredibly productive by, literally, sitting in their office glued to their PC. While s/he interacts electronically with a variety of people and draws on a myriad of information sources, others in the organization might mistakenly assume that this person is closed off from the world, wasting time performing computer-based analysis, or, worse, playing Solitaire. To the extent that individuals are working more electronically and/or remotely, managers will need to learn to trust employees more.

Another interesting implication of technology supported organizational learning is that it presents a potentially difficult new entrant into the organization's technology mix. These are not traditional technologies (e.g., mainframe data base management systems) to support traditional business processes (e.g., transaction processing or inventory management). Thus, managers and technologists may not readily see the value of these new technologies and technology uses. Managers willingness to embrace these new technologies is critical. They must believe that these technologies are worth 
investing in. They also must see that they are building the technological infrastructure to take advantage of new technological opportunities for organizational learning that are sure to come.

The sophistication and power of the enabling technologies for organizational learning are continually improving. The information superhighway comes closer and closer to reality every day. The Internet and World Wide Web continue to grow and improve, with an incredible outpouring of new tools for Web-based collaboration and commerce. In addition, PC-based alternatives for collaboration, such as GSS, Groupware, and desktop video conferencing continue to improve. Technologically, the capabilities and opportunities for supporting organizational learning abound. Similarly, the needs for improved organizational learning become stronger and stronger every day. Given the demands on organizations today and the speed with which competitive forces bring about change, it appears that technology supported organizational learning will very quickly become the rule and not the exception.

\section{REFERENCES}

Argyris, C. and D. A. Schon (1978) Organizational Learning: A Theory of Action Perspective, Reading, MA: Addison-Wesley.

Bessen, J. (1993) Riding the marketing information wave. Harvard Business Review, SeptemberOctober. Pages 150-160.

Daft, Richard L. and George P. Huber (1987) How Organizations Learn: A Communication Framework, Research in the Sociology of Organizations, (5), pp. 1-36.

Daft, Richard L. and N. B. Macintosh (1981) A Tentative Exploration into the Amount and Equivocality of Information Processing in Organizational Work Units, Administrative Science Quarterly (26), pp. 207-224.

Fiol, C. M. and M. A. Lyles (1985) Organizational Learning, Academy of Management Review (10), pp. 803-813.

Garvin, D. A. (1993) Building a learning organization. Garvin. Harvard Business Review, JulyAugust, Pages 78-91.

Hoffer, J., and J.S. Valacich (1993) Group Memory in Group Support Systems: A foundation for Design. In Group Support Systems: New Perspectives, L.M. Jessup \& J.S. Valacich (Eds), New York: Macmillan, pp. 214-229.

Huber, George P. (1991) Organizational Learning: The Contributing Processes and the Literatures, Organization Science, (2:1), pp. 1-28.

Jessup, L. M., \& Valacich, J. S. (1993) Group Support Systems: New Perspectives. Macmillan Publishing Company, New York, New York.

Levitt, Barbara and James G. March (1988) Organizational Learning, Annual Review of Sociology. (14), pp. 319-340.

McKenna, R. (1995) Real-time marketing. McKenna. Harvard Business Review, July-August. Pages 87-95.

Shrivastava, P. (1983) A typology of organizational learning systems, Journal of Management Studies. (20), 1-28.

Zuboff, S. (1984) In the age of the smart machine: The future of work and power. New York, NY: Basic Books, Inc. Publishers. 


\section{SELECTED READINGS}

IT \& Organizational Change

A framework for managing IT-Enabled change. Benjamin and Levinson. Sloan Management Review, Summer 1993. Pages 23-33.

Hurdle the cross-functional barriers to strategic change. Hutt, Walker, and Frankwick. Sloan Management Review, Spring 1995. Pages 22-30.

\section{Virtual Organizations}

Managing by wire. Haeckel and Nolan. Harvard Business Review, September-October 1993. Pages 122-132.

Trust and the virtual organization. Handy. Harvard Business Review, May-June 1995. Pages 42-50.

\section{Technology for Teams}

Technology for teams. Bock and Applegate. Harvard Business School, 1995, \#9-196-008.

Electronic Meeting Systems to support group work: Theory and practice at Arizona. Nunamaker, Dennis, Valacich, Vogel, and George. Communications of the ACM, 1991, 34:7:40-61.

Learning through experience: How companies are really using Groupware, Turrell, Proceedings of Groupware '95 Europe. Pages 149-163.

Chemical Bank: Technology support for cooperative work. Applegate and Stoddard. Harvard Business School, \#9-193-131.

\section{Electronic Commerce \& Internet}

Electronic markets and virtual value chains on the information superhighway. Benjamin and Wigand. Sloan Management Review, Winter 1995. Pages 62-72.

Paving the Information Super highway: Introduction to the Internet. Applegate and Gogan. Harvard Business School, 1995, \#9-195-202.

Electronic Commerce on the World Wide Web: A Case Study. Ives and Jarvenpaa. Southern Methodist University. Case write-up is available on the World Wide Web; URL is http://www.cox.smu.edu/mis/cases/webcase/home.html

Open Market, Inc. Gogan and Applegate. Harvard Business School, 1995, \#9-195-205.

\section{Learning Organization}

The coming of the knowledge-based business, Davis and Botkin. Harvard Business Review, September-October 1994. Pages 165-170.

\section{BIOGRAPHY}

Leonard M. Jessup is an Associate Professor of Accounting and Information Systems in the School of Business at Indiana University. He teaches in various areas of Management and Management Information Systems and has published and presented widely on using computer-based tools to support collaborative work, electronic commerce, and on related topics. With Joseph S. Valacich he 
co-edited the book, Group Support Systems: New Perspectives, and, with his wife, won Zenith Data System's annual Masters of Innovation award.

Joseph S. Valacich is an Associate Professor of Accounting and Information Systems in the School of Business at Indiana University. His current research interests include group decision behavior and the design and investigation of communication and decision technologies to support collaborative group work, including distance learning. His past research has appeared in publications such as MIS Quarterly, Information Systems Research, Management Science, Academy of Management Journal, Communications of the ACM, Decision Science, Organizational Behavior and Human Decision Processes, Journal of Applied Psychology, and Small Group Research. 